\title{
Acceleration of sea-ice melting due to transmission of solar radiation through ponded ice area in the Arctic Ocean: results of in situ observations from icebreakers in 2006 and 2007
}

\author{
Motoyo ITOH, ${ }^{1}$ Jun INOUE, ${ }^{1}$ Koji SHIMADA, ${ }^{1 *}$ Sarah ZIMMERMANN, ${ }^{2}$ \\ Takashi KIKUCHI, ${ }^{1}$ Jennifer HUTCHINGS, ${ }^{3}$ Fiona MCLAUGHLIN, ${ }^{2}$ Eddy CARMACK ${ }^{2}$ \\ ${ }^{1}$ Research Institute for Global Change, Japan Agency for Marine-Earth Science and Technology, 2-15 Natsushima-cho, \\ Yokosuka 237-0061, Japan \\ E-mail: motoyo@jamstec.go.jp \\ ${ }^{2}$ Institute of Ocean Sciences (IOS), Fisheries and Oceans Canada, 9860 West Saanich Road, PO Box 6000, \\ Sidney, British Columbia V8L 4B2, Canada \\ ${ }^{3}$ International Arctic Research Center, University of Alaska Fairbanks, Fairbanks, AK 99775-7340, USA
}

\begin{abstract}
Sea-ice melting processes were inferred from in situ sea-ice and ocean condition data obtained in the Arctic in summer 2006 and 2007. The relationship between ice concentration observed by on-board ice watches and water temperature showed negative correlations. This implies that as ice concentration decreases, the upper ocean becomes warmer due to greater absorption of solar radiation into open water, which promotes ice melting. However, heating of surface water is significant even in regions that were almost completely ice-covered, suggesting that transmitted solar radiation through the ice is also effective at melting sea ice. A simplified ice-upper-ocean coupled model was applied to examine the effect of heat input from open water, thick ice and thin ice. The ponded thin ice is estimated to transmit approximately three times more solar radiation than ponded thick ice. Model results suggest that transmission of solar radiation through ponded ice amplified the ice-albedo feedback mechanism, particularly in thin ice regions. Recently, the extent of old and thick multi-year ice in the Arctic Ocean has been rapidly reduced. As a result, heat input to the upper ocean through the ice is enhanced and ice melt is further accelerated.
\end{abstract}

\section{INTRODUCTION}

Over the past few decades, Arctic sea-ice cover has decreased dramatically (Comiso and others, 2008). In September 2007 it reached a record minimum of $37 \%$ less than the climatological average over 1979-2007. The extent of summer Arctic sea-ice cover is a sensitive indicator of climate change, and is also a potential amplifier of climate change through the ice-albedo feedback mechanism, resulting from the contrast between the albedo of sea ice and open water.

Solar radiation is the dominant energy source driving seaice melting during the summer. Perovich and others (2007) examined satellite-derived ice concentrations and solar radiation, determined from reanalysis data, to show that decreases in sea-ice extent led to an increase in the amount of solar energy absorbed in the upper ocean, in turn accelerating sea-ice decay through ice-albedo feedback. The disposition of incoming solar radiation within sea ice and the upper ocean is critical to the heat and mass balance of sea ice. The heat balance of the ice-upper-ocean coupled system has been examined by simple ice-ocean coupled models (e.g. Steele, 1992; Ebert and others, 1995). However, there have been few observational studies examining the ice-upper-ocean coupled system of the Arctic Ocean. Inoue and others (2008) suggested that the relationship between ice concentration and upper ocean temperature is a good indicator for evaluating the heat balance of solar heat input,

*Present address: Tokyo University of Marine Science and Technology, 4-5-7, Konan, Minato-Ku, Tokyo 108-8477, Japan. sea-ice melting, and heat storage in the ocean mixed layer, by observing the ice and ocean from icebreakers. In summer 2007, ice mass-balance observation demonstrated that there was an extraordinarily large amount of bottom melting of ice in the Canada Basin and that solar heating of the upper ocean was the primary heat source (Perovich and others, 2008). While much of the solar radiation transmitted to the ocean is through open water, a substantial portion is also transmitted through ponded ice. Perovich (2005) and Inoue and others (2008) suggested that there was an effect of solar radiation transmittance through ponded ice on sea-ice melting, based on the year-long drift of the ice station SHEBA (Surface Heat Budget of the Arctic Ocean) in 1998 and on trans-Arctic cruises conducted by the US Coast Guard Cutter (USCGC) Healy in 2005. Further reductions in summer sea-ice extent have continued since these observations were made. Additionally, thick and old ice has decreased rapidly (Maslanik and others, 2007). Transmitted solar radiation through the ice may be enhanced because of decreasing average sea-ice thickness in the Arctic Ocean. To understand the sea-ice melting process under recent reduced-ice conditions, additional in situ ice and ocean observations are needed.

We observed sea-ice cover and upper ocean conditions from icebreakers in the Arctic Ocean (Fig. 1). From August to September 2006 and from July to August 2007, the Canadian Coast Guard Ship (CCGS) Louis S. St-Laurent operated in the Canada Basin. From July to September 2007, the Research Vessel (R/V) Polarstern operated in the eastern Arctic Ocean. The purpose of this study was to describe sea-ice melting processes, based on ice and ocean conditions data, obtained 

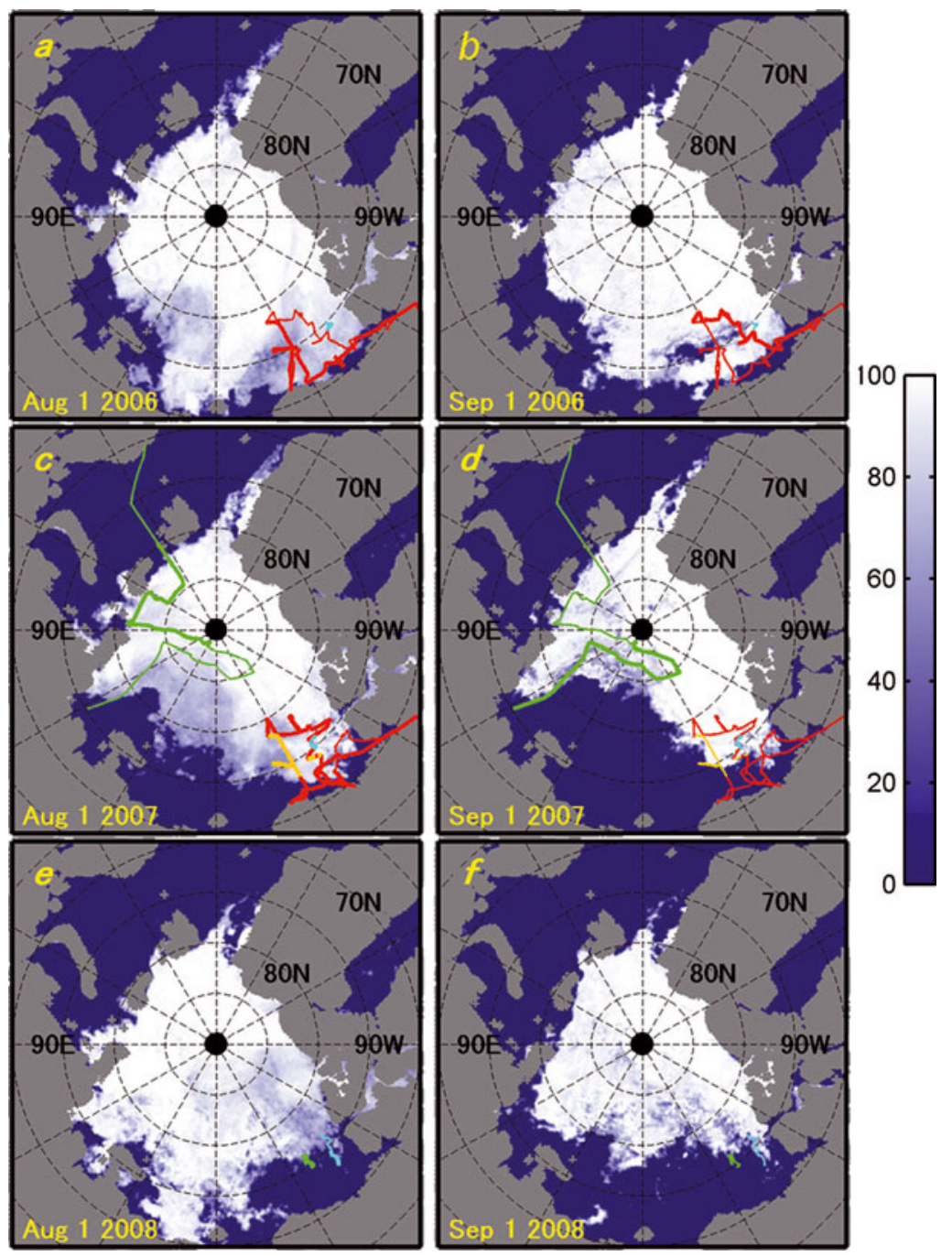

Fig. 1. Time series of sea-ice concentration in the Arctic Ocean on (a) 1 August 2006, (b) 1 September 2006, (c) 1 August 2007, (d) 1 September 2007, (e) 1 August 2008 and (f) 1 September 2008, deduced from Advanced Microwave Scanning Radiometer for Earth Observing System (AMSRE) data provided by the US National Snow and Ice Data Center (NSIDC). The NASA Team algorithm is used. The cruise tracks are superimposed. Red line in (a) and (b) denotes the cruise tracks of CCGS Louis S. St-Laurent in 2006. Light blue line in (a) and (b) denotes the trajectory of ITP3/IMB2005B from July to August in 2006. Red line in (c) and (d) denotes the cruise tracks of CCGS Louis S. St-Laurent in 2007. Yellow line in (c) and (d) denotes the FYI region during cruise CCGS Louis S. St-Laurent in 2007. Green line in (c) and (d) denotes the cruise track of R/V Polarstern in 2007. Light blue line in (c) and (d) denotes the trajectory of ITP6/IMB2006C from July to August in 2007. Light blue and green lines in (e) and (f) denote the trajectories of ITP13/IMB2007E and ITP18/IMB2007F from July to August in 2008. Thick lines in (a), (c) and (e) ((b), (d) and (f)) indicate the ship position in August (September).

during the summer from icebreakers in the Arctic, and to compare these results with those of a simple ice-upperocean coupled model.

Table 1. Time interval of visual ice observation during PS2007, LSSL2006 and LSSL2007. Dashes indicate the parameter was not observed

\begin{tabular}{|c|c|c|c|}
\hline & PS2007 & LSSL2006 & LSSL2007 \\
\hline Ice concentration & Every hour & Every 2 hours & Every hour \\
\hline $\begin{array}{l}\text { Melt pond } \\
\text { fraction }\end{array}$ & Every hour & - & $\begin{array}{c}\text { Every } 2-6 \text { hours } \\
\text { after } 5 \text { August }\end{array}$ \\
\hline Ice thickness & Every hour & - & $\begin{array}{c}\text { Every } 2-6 \text { hours } \\
\text { after } 5 \text { August }\end{array}$ \\
\hline $\begin{array}{l}\text { Ice type (MYI, FYI } \\
\text { fraction) }\end{array}$ & - & - & Every $2-6$ hours \\
\hline
\end{tabular}

\section{OBSERVATIONS}

The CCGS Louis S. St-Laurent operated in the Canada Basin from the beginning of August until mid-September 2006 and from the end of July until the end of August 2007 (hereafter, we call these cruises LSSL2006 and LSSL2007, respectively). From the end of July until the end of September 2007, the German R/V Polarstern operated in the eastern Arctic Ocean (hereafter PS2007). The cruise routes of LSSL2006, LSSL2007 and PS2007 are shown in Figure 1, superimposed on satellite images of sea-ice concentrations.

Temperature and salinity data obtained from conductivity-temperature-depth (CTD) units and expendable CTD (XCTD) were used in this study. Visual observations of seaice cover were made, according to the methods of Worby and others (1999), from the bridge while the ship was moving through the ice (Fig. 2). For each visual observation, we estimated ice concentration, ice type and ice thickness. Time intervals for each parameter are listed in Table 1. In this 

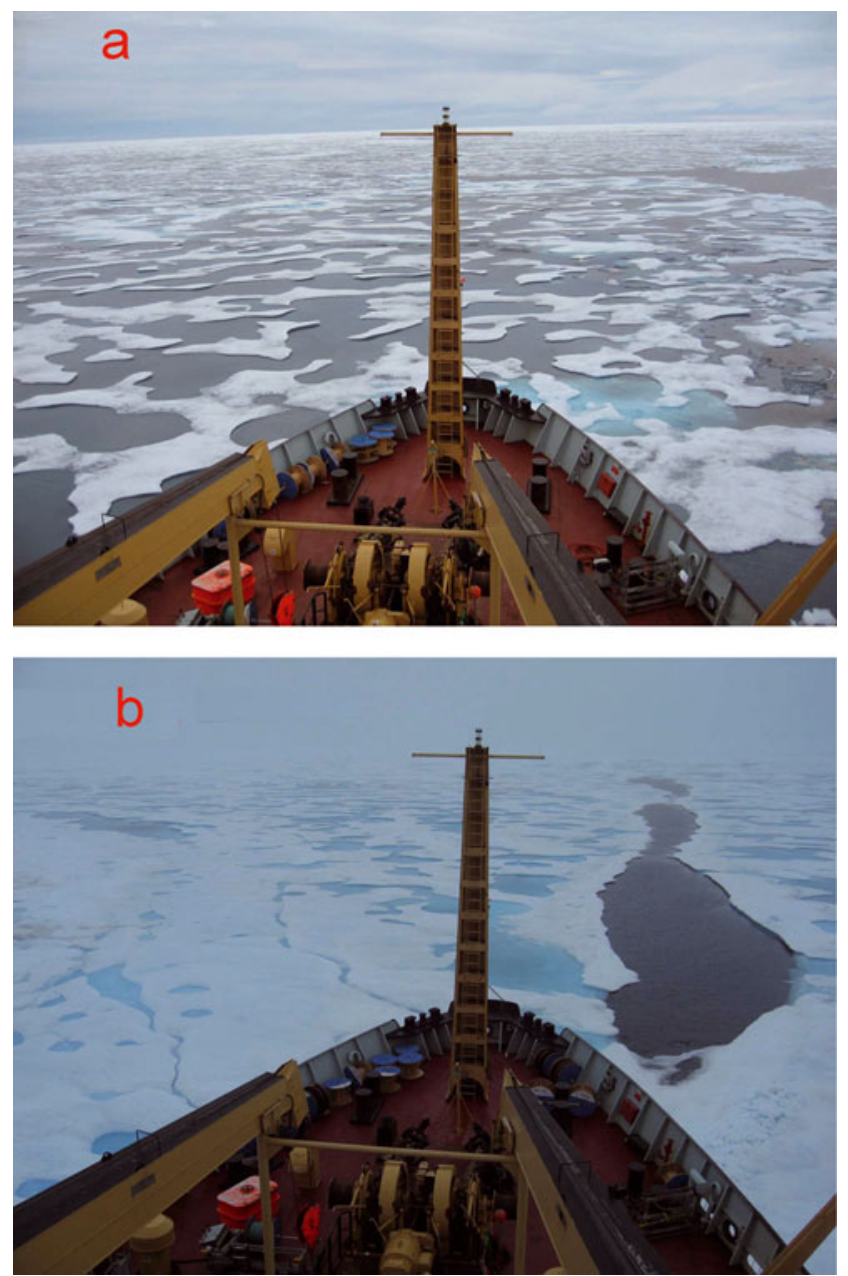

Fig. 2. Photographs of the ice cover taken from the bridge of LSSL2007 at (a) $76^{\circ} \mathrm{N}, 150^{\circ} \mathrm{W}$ and (b) $77^{\circ} \mathrm{N}, 135^{\circ} \mathrm{W}$.

study, we used data on the percentages of open water, ponds, ice, and ice type and thickness.

In addition to the ship-based data, ice and ocean data obtained from ice mass-balance buoys (IMBs) and icetethered profilers (ITPs) were used. Observations of the ice surface and bottom melt were made using autonomous IMBs (D.K. Perovich and others, http://imb.crrel.usace.army.mil) that drifted with the ice pack. ITPs, which collected temperature and salinity profiles beneath the ice to $800 \mathrm{~m}$ (Krishfield and others, 2008), were also deployed. Here, ocean and ice data were examined using ITPs (ITP3, ITP6, ITP13, ITP18) and co-located IMBs (IMB2005B, IMB2006C, IMB2007E, IMB2007F) in the Canada Basin during the melting seasons in 2006, 2007 and 2008 (Fig. 1).

\section{ICE AND OCEAN CONDITIONS}

Figure 1 shows the time series of sea-ice concentrations during summer in 2006, 2007 and 2008. Summer sea-ice extent has decreased significantly since the late 1990s. Seaice extent in 2006, 2007 and 2008 has shrunk compared with that existing before the 2000s. In particular, in September 2007 the extent of Arctic sea-ice cover reached a record minimum, which was $37 \%$ less than the climatological average over the period since September 1979 (Maslanik and others, 2007; Comiso and others, 2008). The retreat was particularly pronounced on the Pacific side of the Arctic Ocean. In most of the observational area of LSSL2007, the sea ice had completely melted by midSeptember. In September 2006 and 2008, the sea ice did not retreat as much as it did in 2007. Interestingly, a polynya appeared above Northwind Ridge $\left(\sim 76^{\circ} \mathrm{N}\right.$, $\left.160^{\circ} \mathrm{W}\right)$ in 2006.

Figures 3-5 show the distribution of the observed ice and ocean characteristics along the cruise routes of PS2007, LSSL2006 and LSSL2007, respectively. Temperature and salinity were approximately uniform from near the surface to depths of 10-25 m (data not shown). Thus, we used the average temperature and salinity from 8 to $12 \mathrm{~m}$ as the surface mixed-layer temperature and salinity. Temperature above the freezing point of local sea water $(\Delta T)$ is a good indicator of how much the upper ocean is heated by solar radiation, particularly in areas where salinity is not horizontally uniform.

The temperature was typically above freezing even in regions that were almost completely ice-covered (>90\% cover), as shown in Figures 3-5. During LSSL2007, $\Delta T$ was very high in the open-water and marginal-ice regions of the southern Canada Basin. We discuss this in more detail in sections 4 and 5 . Melt ponds covered $27 \%$ and $31 \%$ of the sea-ice area during PS2007 and LSSL2007, respectively. The average ice thicknesses during PS2007 and LSSL2007 were 0.9 and $1.0 \mathrm{~m}$, respectively. Average ice thickness in the central Arctic (north of $85^{\circ} \mathrm{N}$ ) was $0.8 \mathrm{~m}$ in 2007 and $1.9 \mathrm{~m}$ in 2005 from trans-Arctic observations (Perovich and others, 2009), suggesting decreasing ice thickness from 2005 to 2007. Melt pond fraction and ice thickness observations were not carried out during LSSL2006.

\section{RELATIONSHIPS BETWEEN ICE CONCENTRATION AND WATER TEMPERATURE}

The relationship between ice concentration and temperature is a consequence of heat balance in the ice-upper-ocean coupled system, maintained by solar radiation, sea-ice melting, and heat storage in the ocean mixed layer (Ohshima and others, 1998; Inoue and others, 2008). Here we describe the relationships between ice concentrations observed by on-board ice watch and upper ocean temperatures obtained by CTD and XCTD observation. Because local heat balances in the ice-upper-ocean system hold over 20-30 km spatial scales (Ohshima and others, 1998; Nihashi and others, 2005), ice and ocean data in areas where the ice concentration was $>50 \%$ were averaged to a $25 \mathrm{~km}$ spatial running mean. We refer to PS2007 and LSSL2006 as cases I and II, respectively. We divided the stations of LSSL2007 into two areas, because sea-ice thickness and the relationship between ice concentration and temperature in the southern Canada Basin were very different from those in the northern Canada Basin. We refer to the thick multi-year ice (MYI) region (ice thickness $h=1.2 \mathrm{~m}$ ) and the thin first-year ice (FYI) region $(h=0.7 \mathrm{~m})$ as cases III and IV, respectively. During LSSL2007, $\Delta T$ was very high in the open-water and marginal-ice regions of the southern Canada Basin. Additionally, the $\Delta T$ from 6 to 11 August in the southern Canada Basin along $150^{\circ} \mathrm{W}$ below $78^{\circ} \mathrm{N}$ was higher than that from 11 to 19 August in the northern Canada Basin above $78^{\circ} \mathrm{N}$, although the ice concentration remained high (80-90\%) from 6 to 19 August. In the former region, ice thickness was relatively low $(<1 \mathrm{~m})$ and the fraction of MYI was almost zero (see Fig. 2a). As these stations are 


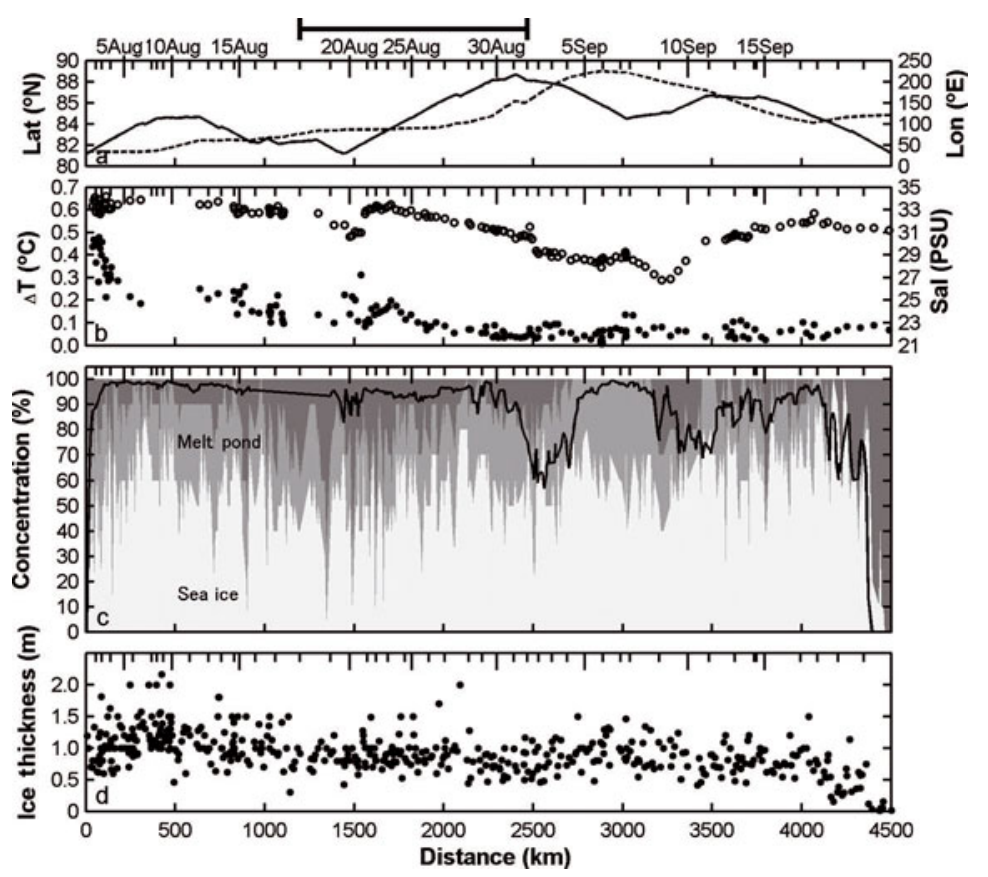

Fig. 3. Ice and ocean observational data from PS2007 cruise. (a) Solid and dashed curves indicate latitude and longitude of ship position corresponding to the cruise track. Solid line indicates the analysis areas in Figure 6a. (b-d) Distribution of (b) temperature and salinity between 8 and $12 \mathrm{~m}$ derived from the CTD and XCTD data (filled cricles: temperature; open circles: salinity), (c) ice concentration derived from ice-watch data (dark grey: open water; light grey: melt pond; white: sea ice) and ice concentration deduced from AMSRE data (solid curve) and (d) ice thickness obtained by the ice watch.

$100-1000 \mathrm{~km}$ from the ice margin, heat advection from open-water areas is not a reasonable explanation.

Figure 6 shows the ice-concentration $\left(A_{\mathrm{i}}\right)-\Delta T$ plots (hereinafter CT plots) during August for cases I-IV. In all cases, $\Delta T$ increased as the ice concentration decreased, consistent with results obtained from Antarctic cruises off Syowa station (Ohshima and others, 1998) and in the Ross Sea (Nihashi and others, 2005), and Arctic cruises in the Canada Basin (Inoue and others, 2008). This indicates that as ice concentration decreases, $\Delta T$ increases due to the greater absorption of solar radiation into open water (ice-albedo feedback). Correlation coefficients between $\Delta T$ and $1 / A_{\mathrm{i}}$ for cases I-III were above the 99\% confidence level for significance. If heat advection from open water outside the ice edge, vertical heat flux from below the mixed layer, and transmittance of solar radiation through the ice are neglected, $\Delta T$ should approach $0^{\circ} \mathrm{C}$ towards $100 \%$ ice concentration on a CT plot (Ohshima and others, 1998; Nihashi and others, 2005; Inoue and others, 2008). However, $\Delta T$ was above zero even in almost completely ice-covered regions (e.g. ice concentrations of $>90 \%$ ). Heat advection from open-water areas is not a reasonable explanation for this increased $\Delta T$ (hereinafter $\Delta T$-gain), because the $\Delta T$ was above zero even $100-1000 \mathrm{~km}$ from the

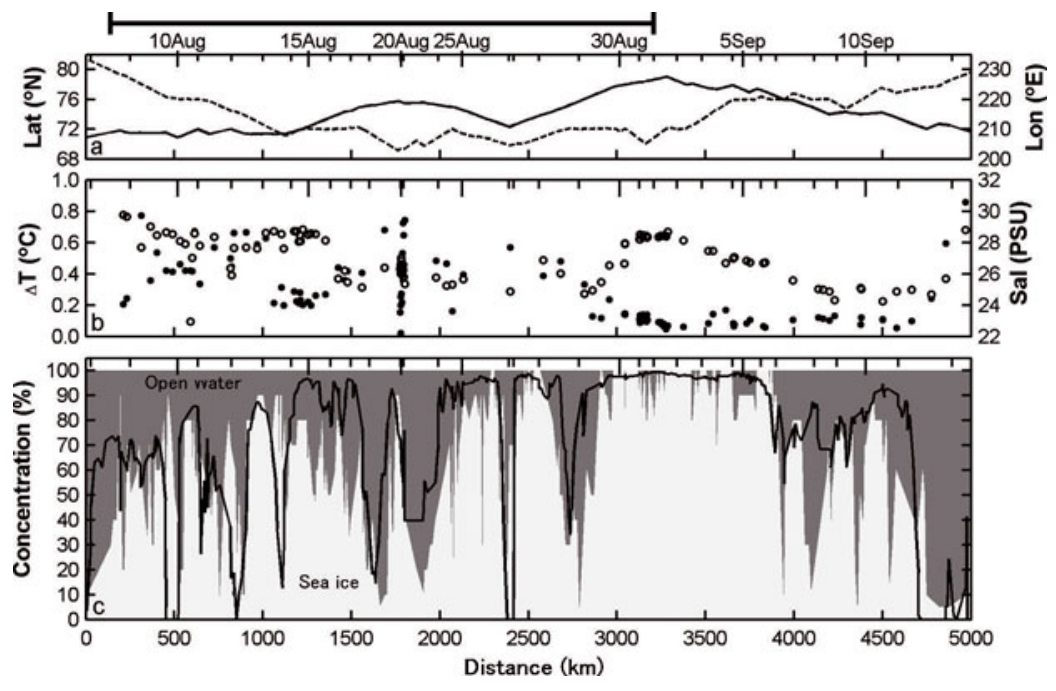

Fig. 4. Ice and ocean observational data from LSSL2006 cruise. (a) and (b) correspond to Figure 3a and b, respectively. Solid line in (a) indicates the analysis areas in Figure 6b. (c) Distribution of ice concentration derived from ice-watch data (dark grey: open water; white: sea ice) and ice concentration deduced from AMSRE data (solid curve). Melt pond fraction and ice thickness observation were not carried out. 


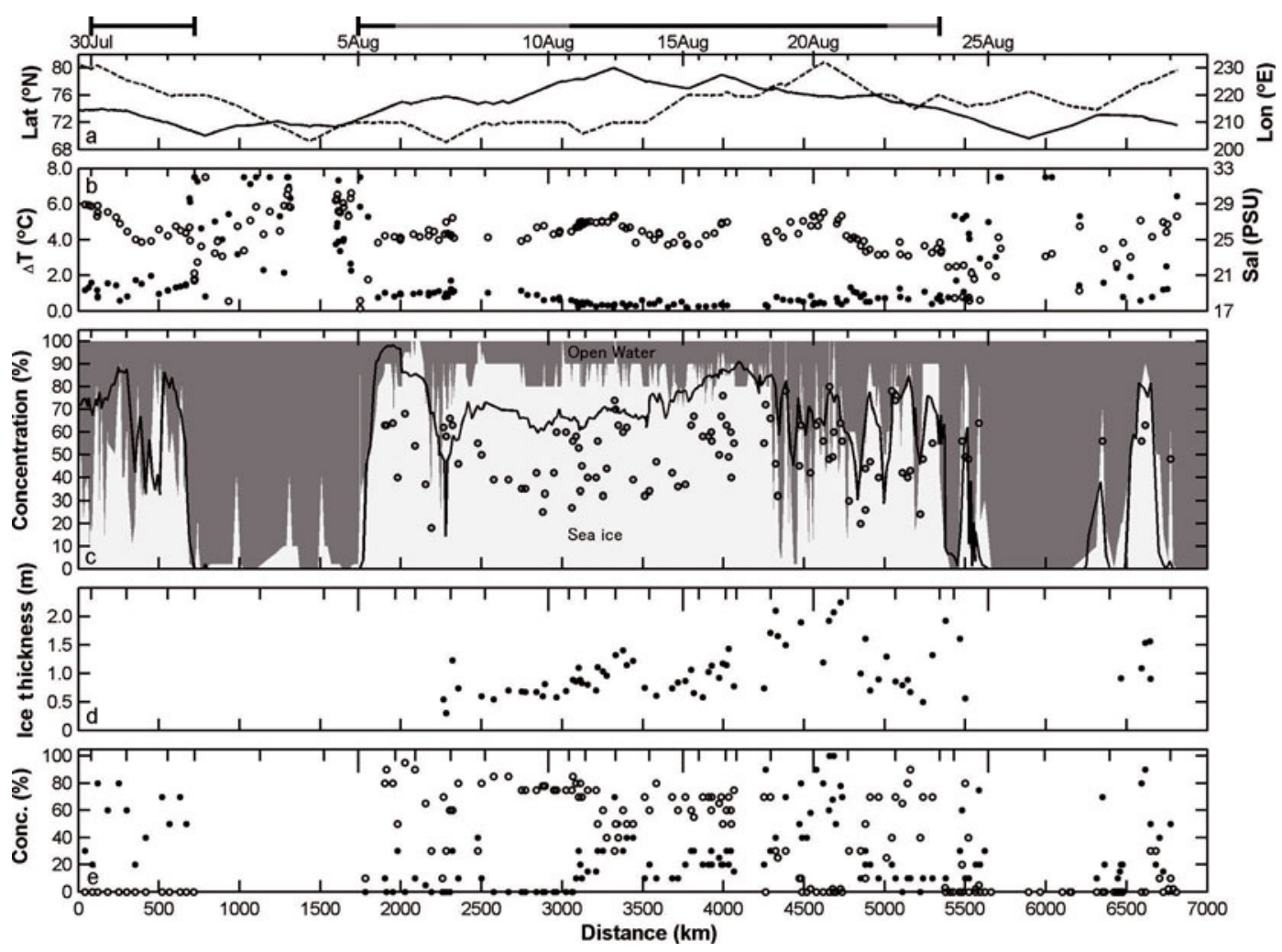

Fig. 5. Ice and ocean observational data from LSSL2007 cruise. (a), (b) and (d) correspond to Figure 3a, b and d, respectively. (c, e) Distribution of (c) ice concentration derived from ice-watch data (dark grey: open water; white: sea ice; light gray dots: melt pond fraction) and ice concentration deduced from AMSRE data (solid line) and (e) fractions of multi-year ice (MYI) and first-year ice (FYI) from ice watch (filled circles: MYI; open circle: FYI). Sums of the fractions of MYI and FYI are equal to $A_{\mathrm{i}}$. Black and gray lines in (a) indicate the analysis areas in Figure $6 \mathrm{c}$ and $\mathrm{d}$.
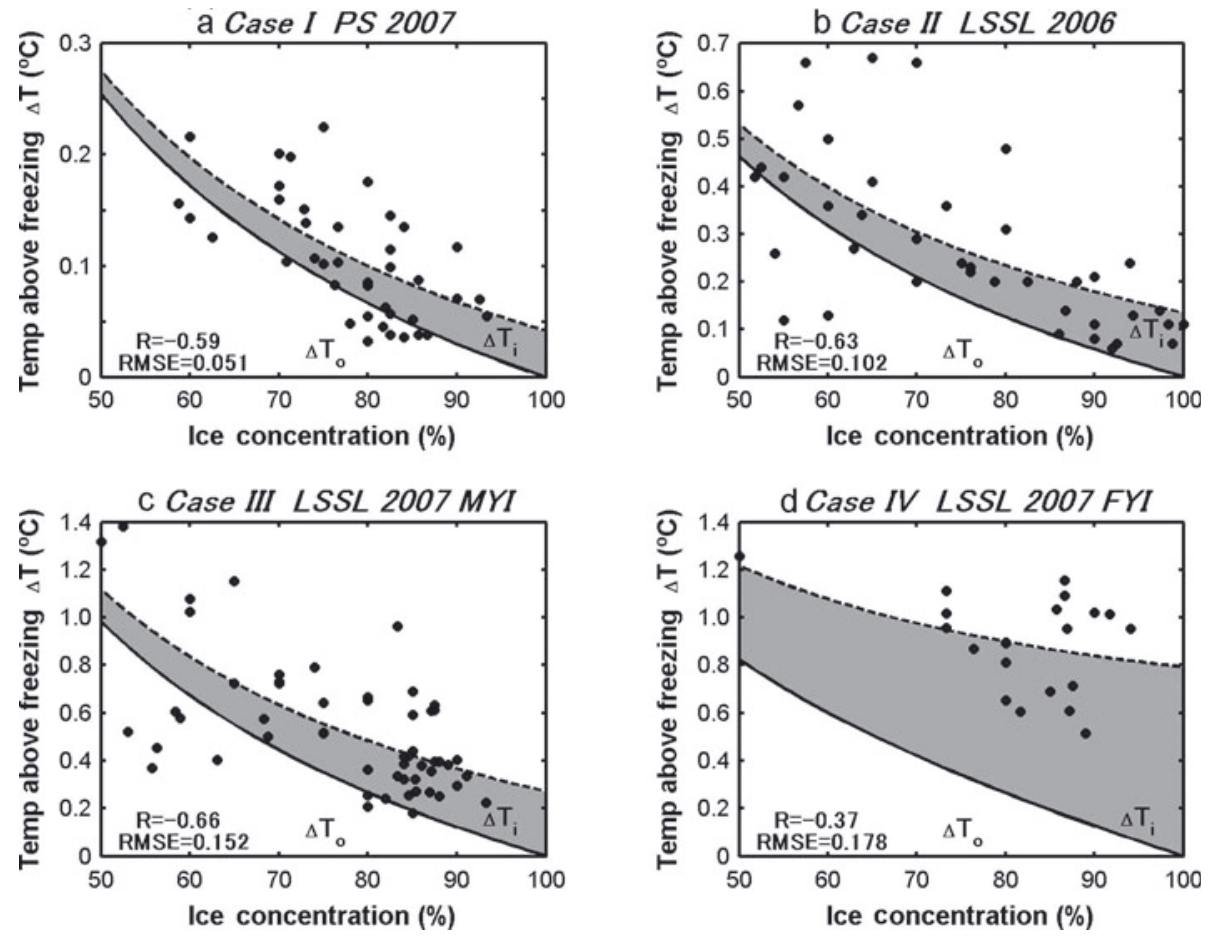

Fig. 6. Scatter plots of the ice concentration versus temperature above the freezing point ( $\Delta T$ ) from (a) case I, (b) case II, (c) case III and (d) case IV. Ice concentration derived from on-board ice-watch data and $\triangle T$ calculated from the CTD and XCTD data are spatially averaged using a $25 \mathrm{~km}$ running mean. The dashed curves are regression curves (linear with respect to $1 / A_{\mathrm{i}}$ ) based on the observations. $R$ and RMSE indicate the correlation coefficient and root-mean-square error, respectively. The solid curve is the same regression curve after subtracting the quantity $\left(\Delta T\right.$-gain $\left.{ }_{A_{\mathrm{i}}=100 \%} A_{\mathrm{i}}\right)$, which we take as the warming caused by transmission of solar radiation through the ponded ice. 

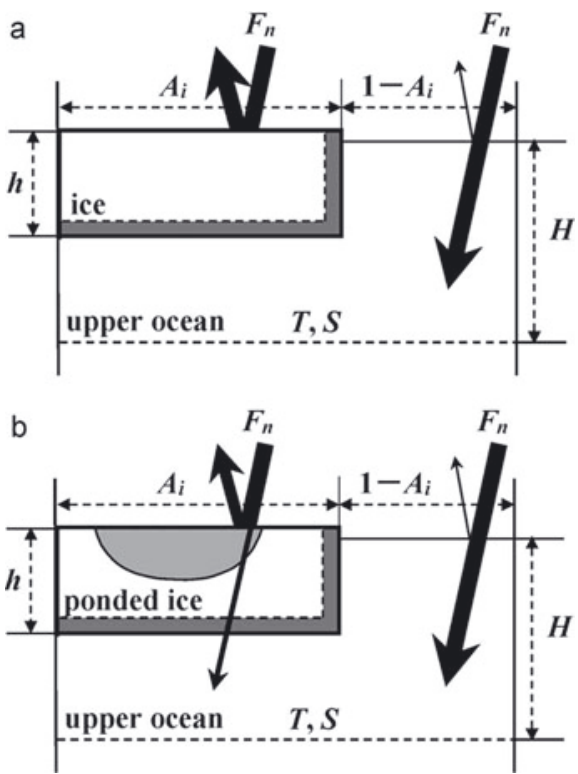

Fig. 7. A schematic illustration of the coupled ice-ocean model. $A_{\mathrm{i}}$ is ice concentration, so $1-A_{\mathrm{i}}$ is the open-water fraction. $h$ is ice thickness. The upper ocean is simply represented by one layer of thickness $H$ with a uniform temperature, $T$, and salinity, $S$. (a) Incident solar flux at the surface, $F_{n}$, is supplied only over the open-water area. (b) Transmitted solar radiation through the ponded ice area is included as well as heat flux into the open-water area.

ice edge. Vertical heat flux from below the mixed layer can also be neglected due to strong stratification during the Arctic summer. Thus, transmittance of solar radiation through ponded ice apparently affected $\Delta T$-gain in largely ice-covered regions, consistent with the results of Inoue and others (2008).

According to the analytic solution obtained by Ohshima and others (1998), $\Delta T$ is inversely proportional to $A_{\mathrm{i}}$. In fact, CT plots from Ohshima and others (1998), Nihashi and others (2005) and Inoue and others (2008) show inverse proportionality. Thus, we applied simple regression lines $\left(\Delta T=\alpha / A_{\mathrm{i}}+\beta\right)$, similar to Inoue and others (2008). The dashed curves in Figure 6 are regression curves based on the observations for each area. The total $\Delta T$-gain is the sum of the contributions of heat from open water and ponded ice. $\Delta T$-gain where the ice concentration is $100 \%(\Delta T$ gain $_{A_{i}=100 \%}$ ) should be $\Delta T$-gain only resulting from heat transmittance through ponded ice $\left(\Delta T_{\mathrm{i}}\right)$. Therefore, $\Delta T$-gain resulting from heat input through open water $\left(\Delta T_{\mathrm{o}}\right)$ can be obtained by subtracting the $\Delta T$-gain $A_{A_{i}=100 \%}$, weighted by $A_{\mathrm{i}}$, from the total $\Delta T$-gain. We note that the discussion here assumes that pond fraction and transmittance of ponded area does not change as $A_{\mathrm{i}}$ decreases. The solid curves in Figure 6 are adjusted regression lines for $\Delta T_{\mathrm{O}}$ ( $\Delta T$-gain$\Delta T$-gain $\left.A_{A_{i}=100 \%} A_{\mathrm{i}}\right)$. The area enclosed between these two curves indicates the $\Delta T_{\mathrm{i}}$ induced by $A_{\mathrm{i}}$. In a specific example, to gain $0.068^{\circ} \mathrm{C}$ of $\Delta T$ when $90 \%$ of the area was covered by ponded ice, total $\Delta T$-gain was partitioned into $\Delta T_{\mathrm{O}}=0.03^{\circ} \mathrm{C}$ and $\Delta T_{\mathrm{i}}=0.038^{\circ} \mathrm{C}$ in Figure 6a. Although the contribution of $\Delta T_{\mathrm{O}}$ was the dominant heat source over most of the area, the role of $\Delta T_{\mathrm{i}}$ was considerable beneath largely ice-covered areas. The contribution of $\Delta T_{\mathrm{i}}$ to total $\Delta T$-gain was greater than that of $\Delta T_{\mathrm{o}}$ where the ice concentration was more than $88 \%, 82 \%, 83 \%$ and $65 \%$, for cases I, II, III and IV, respectively.
Even at the same ice concentrations, $\Delta T$-gains were different between cases I, II, III and IV (Fig. 6). The $\Delta T_{\mathrm{i}}$ was anomalously high in case IV (LSSL2007 FYI region). As these stations were far from the north of the ice margin (100$1000 \mathrm{~km})$, heat input due to transmitted solar radiation through the ice rather than horizontal heat advection from open-water areas is a reasonable explanation for this $\Delta T_{\mathrm{i}}$. We examine $\Delta T$-gain more closely in section 5 , using a simple ice-ocean coupled model.

From PS2007, only data from the $90^{\circ}$ E section are shown in Figure 6. Sections along $34^{\circ} \mathrm{E}$ and $60^{\circ} \mathrm{E}$, in the Nansen Basin, also showed negative correlations in the CT plots, although $\Delta T$-gain was higher than in case I. A possible explanation for this might be differences in solar radiation because of the timing of observations and/or the horizontal heat advection of Atlantic water from open water. As the number of stations in this area was so small, we did not include them in this study.

\section{SIMPLE MODELS TO EVALUATE HEAT BALANCE OF ICE-UPPER-OCEAN COUPLED SYSTEM}

In this section, we develop a simple model to examine the observed ice concentration and temperature relations, which is a consequence of the heat balance in the iceupper-ocean coupled system in the Arctic melting season.

\subsection{A model without transmitted solar radiation through the ponded ice}

\subsubsection{Model description}

As heat input into the ice-upper-ocean system mainly occurs in open water when the ice concentration is relatively low, we began by examining the observed $\mathrm{CT}$ plot using a simple ice-upper-ocean coupled model in which sea-ice bottom and lateral melting are caused only by the heat input through open water (as proposed by Ohshima and Nihashi (2005) and Inoue and others (2008)). As shown in section 4, we separately evaluated the surface water heating caused by heat input through open-water areas $\left(\Delta T_{\mathrm{o}}\right)$ and through ponded ice areas $\left(\Delta T_{\mathrm{i}}\right)$, using simple regression curves applied to observed CT plots (Fig. 6). Here we briefly describe the model, schematically shown in Figure 7a. The upper ocean is represented simply by a mixed layer of thickness $H$ with a uniform temperature, $T$, and salinity, $S$. Heat and water exchange with the ocean below the mixed layer are also assumed to be zero due to the strong stratification during the Arctic summer. The net heat flux to the ocean over the ice-covered area, $A_{i}$, is assumed to be zero; thus, the surface net heat flux would only be supplied in the open-water area, $1-A_{i}$. If sea-ice melting is caused by this heat input, the heat balance of the upper ocean can be given by

$$
c_{\mathrm{w}} \rho_{\mathrm{w}} H \frac{\mathrm{d} T}{\mathrm{~d} t}=F_{\mathrm{n}}\left(1-A_{\mathrm{i}}\right)\left(1-\alpha_{\mathrm{o}}\right)+L_{\mathrm{f}} \rho_{\mathrm{i}}\left(A_{\mathrm{i}} \frac{\mathrm{d} h}{\mathrm{~d} t}+h \frac{\mathrm{d} A_{\mathrm{i}}}{\mathrm{d} t}\right),
$$

where $F_{\mathrm{n}}$ is the incident solar flux at the surface, $C_{\mathrm{w}}=3990$ $\mathrm{J} \mathrm{kg}^{-1} \mathrm{~K}^{-1}$ is the heat capacity of sea water, $\rho_{\mathrm{w}}=1026 \mathrm{~kg} \mathrm{~m}^{-3}$ and $\rho_{\mathrm{i}}=900 \mathrm{~kg} \mathrm{~m}^{-3}$ are the densities of sea water and sea ice, respectively, $L_{f}$ is the latent heat of fusion for sea ice and $t$ is time. We used a fixed value of $L_{\mathrm{f}}=0.316 \mathrm{MJ} \mathrm{kg}^{-1}$, corresponding to a MYI salinity of 2 psu (Eicken and others, 1995). The ice thickness, $h$, is defined as the average thickness, and $\alpha_{\mathrm{o}}=0.06$ is the surface albedo of open water. 

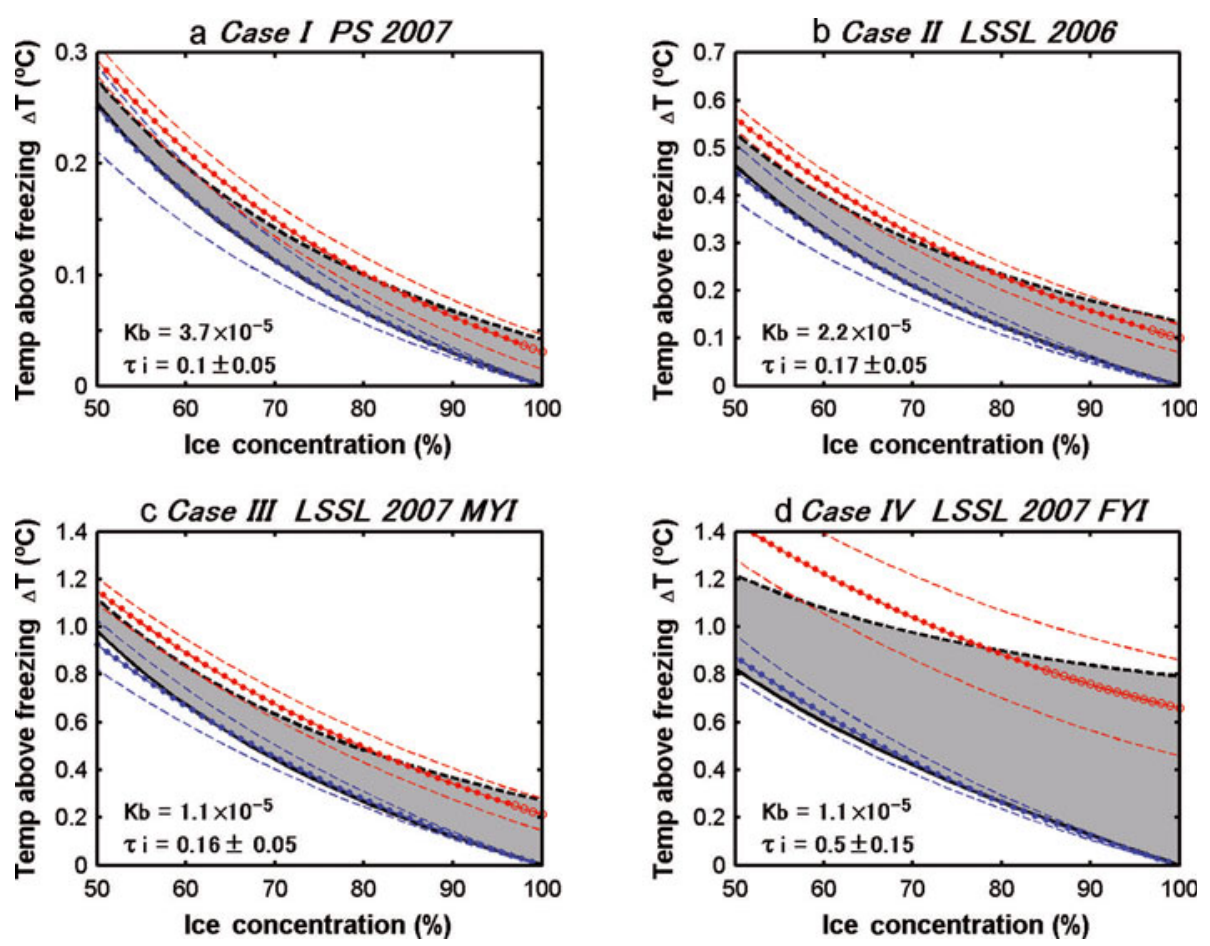

Fig. 8. Blue and red solid circles are model results without and with effect of solar radiation transmittance through the ponded ice area after 15 days of time integration. Convergent curves are linearly extrapolated toward $100 \%$ ice concentration with respect to $1 / A_{\mathrm{i}}$. Open blue and red circles indicate the extrapolated values. Dashed blue curves show the results with $F_{\mathrm{n}}$ changed by $\pm 15 \mathrm{~W} \mathrm{~m}^{-2}$. Dashed red curves show the results with $\tau_{\text {i }}$ changed by \pm 0.05 (cases I, II and III) or \pm 0.15 (case IV). The solid and dashed black curves are the same as shown in Figure 6.

We assume that sea ice melts at the bottom and lateral faces at a rate proportional to the difference between the water temperature and the freezing point (i.e. $\Delta T$ ). We implicitly assume that the open water is well mixed with the water just beneath the ice. Bottom melting is parameterized as

$$
-\rho_{\mathrm{i}} L_{\mathrm{f}} A_{\mathrm{i}} \frac{\mathrm{d} h}{\mathrm{~d} t}=C_{\mathrm{w}} \rho_{\mathrm{w}} A_{\mathrm{i}} K_{\mathrm{b}} \Delta T,
$$

where $K_{\mathrm{b}}$ is the bulk heat transfer coefficient between ice and ocean. Lateral melting is parameterized in a similar way to Hibler (1979), as

$$
\frac{\mathrm{d} A_{\mathrm{i}}}{\mathrm{d} t}=\frac{\mathrm{d} h^{*}}{\mathrm{~d} t} \frac{A_{\mathrm{i}}}{2 h^{*}} .
$$

In this equation, $h^{*}$ is defined as an effective sea-ice thickness averaged over each of the gridcells, including the open-water fraction. Thus, $h^{*}$ can be regarded as the total ice volume per unit area. Note that the actual average ice thickness is $h=h^{*} / A_{\mathrm{i}}$ in this model.

Using this model, we discuss the relationships between the ice fraction and the temperature above the freezing point. On the basis of in situ observations from the icebreakers, the surface mixed layer thickness, $H$, and initial sea-ice thickness, $h_{0}$, were set to the values listed in Table 2. The incident solar flux at the surface, $F_{n}$, was set to one-third of the shortwave radiation at the top of the atmosphere for each area using Key's (2001) radiative transfer model, as a follow-on to the results of Inoue and others (2005, 2008). The $F_{\mathrm{n}}$ averaged over the period from 5 days before observations began until the end of the observation period for the study area noted in Table 2 was used for model calculations, because 10-15 days corresponds to the convergence timescales of the model (Ohshima and others, 1998; Ohshima and Nihashi, 2005; Inoue and others, 2008). The model values of $F_{\mathrm{n}}$ are listed in Table 2 .

Table 2. Value of each parameter for simple ice-ocean model for PS2007, LSSL2006 and LSSL2007 (both MYI and FYI). $F_{\mathrm{n}}$ is incident solar flux at the surface, $h_{0}$ is initial ice thickness, $H$ is mixed-layer thickness, $K_{\mathrm{b}}$ is heat transfer coefficient between ice and ocean, and $\tau_{\mathrm{i}}$ is solar radiation transmittance through ponded ice area. $F_{\mathrm{n}}$ and wind speed data used in Figure 12 are averaged in the bottom row

\begin{tabular}{lccc}
\hline & (I) PS2007 & (II) LSSL2006 & (III) LSSL2007 (MYI) \\
\hline$F_{\mathrm{n}}\left(\mathrm{W} \mathrm{m}{ }^{-2}\right)$ & 90 & 103 & 124 \\
$h_{0}(\mathrm{~m})$ & 1.1 & 1.1 & 1.2 \\
$H(\mathrm{~m})$ & 15 & 13 & 0.7 \\
$K_{\mathrm{b}}\left(10^{-5} \mathrm{~m} \mathrm{~s}^{-1}\right)$ & 3.7 & 2.2 & 10 \\
$\tau_{\mathrm{i}}$ & 0.1 & 0.17 & 1.1 \\
Area for $F_{\mathrm{n}}$ and wind & $80-90^{\circ} \mathrm{N}, 80-170^{\circ} \mathrm{E}$ & $70-80^{\circ} \mathrm{N}, 130-160^{\circ} \mathrm{W}$ & $70-80^{\circ} \mathrm{N}, 130-160^{\circ} \mathrm{W}$ \\
\end{tabular}




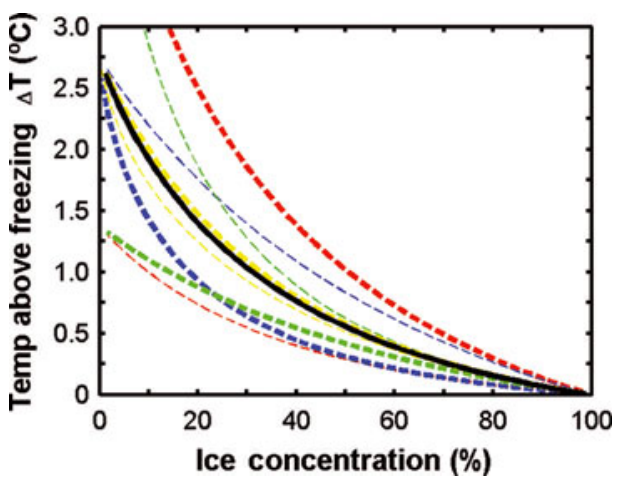

Fig. 9. Relationship between ice concentration and upper-ocean temperature above freezing, derived from the ice-ocean coupled model illustrated in Figure 7a. The solid black curve shows the base case with initial ice thickness set to $1.2 \mathrm{~m}, F_{\mathrm{n}}$ set to $120 \mathrm{~W} \mathrm{~m}^{-2}$, and $K_{\mathrm{b}}$ set to $2.0 \times 10^{-5} \mathrm{~m} \mathrm{~s}^{-1}$. Red, blue, yellow and green thick (thin) dotted curves indicate cases with $F_{\mathrm{n}}, K_{\mathrm{b}}, h$ and $H$, respectively, doubled (halved) from the base case.

\subsubsection{Results}

The CT relationship converges asymptotically with a timescale of 10 days regardless of the initial conditions of $A_{\mathrm{i}}$ and $\Delta T$ (Ohshima and others, 1998; Ohshima and Nihashi, 2005; Inoue and others, 2008). $\Delta T$ is zero under completely ice-covered areas, because solar radiation transmittance through the ice is not treated in this model. Therefore, the modeled $\Delta T$-gain is comparable to the analyzed $\Delta T_{\mathrm{o}}$ calculated from the linear regression curve shown by a solid curve in Figure 6 . The characteristics of the convergent curves are determined by parameters, $F_{\mathrm{n}}, K_{\mathrm{b}}, h$ and $H$. Because $h$ and $H$ are observable parameters and $F_{\mathrm{n}}$ can be obtained as described above, $K_{\mathrm{b}}$ is the least-known parameter. The modeled $\mathrm{CT}$ relationship can be used to estimate the bulk heat transfer coefficient between ice and ocean, $K_{\mathrm{b}}$, by least-squares fitting the analyzed $\Delta T_{\mathrm{o}}$. The blue curves with the values of $K_{\mathrm{b}}$ noted in Figure 8 provided the best fit to the observed CT plots for cases I-IV. In section 5.1.1 we show that these derived values of $K_{\mathrm{b}}$ seems to be physically reasonable. Using estimated values of $K_{\mathrm{b}}$, the modeled CT relationships agreed with the analyzed $A_{\mathrm{i}}-\Delta T_{\mathrm{O}}$ relationships (Fig. 8), suggesting that the model can approximately describe the heat balance of the ice-upper-ocean system that includes only heat input through open water.

Here we briefly examine the dependence of the CT plots on the controlling factors, $F_{\mathrm{n}}, K_{\mathrm{b}}, h$ and $H$. In a test case, $F_{\mathrm{n}}$ $K_{\mathrm{b}}$ and $H$ were set to $120 \mathrm{~W} \mathrm{~m}^{-2}, 2.0 \times 10^{-5} \mathrm{~m} \mathrm{~s}^{-1}$ and $13 \mathrm{~m}$, corresponding to typical summertime values in the Arctic. Initial ice thickness is set to $1.2 \mathrm{~m}$. To examine the sensitivity of the calculated CT curve to variations in $F_{\mathrm{n}}, K_{\mathrm{b}}, h$ and $H$, cases with these parameters halved and doubled are shown in Figure 9. In regions with relatively high ice cover, the

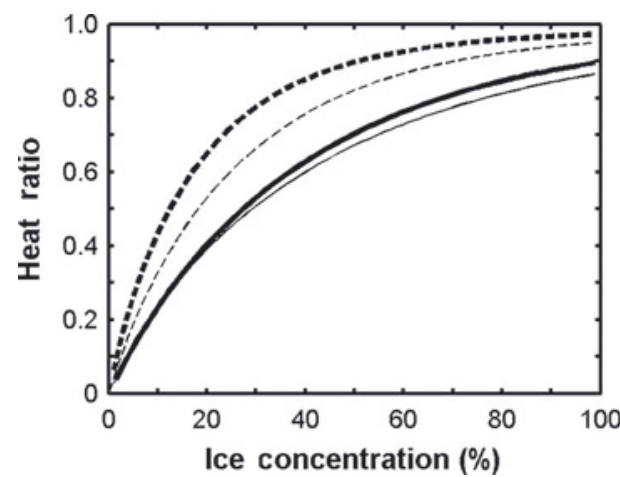

Fig. 10. Ratio of the heat used for ice melt to the heat input through open water as a function of ice concentration, derived from the iceocean coupled model illustrated in Figure $7 \mathrm{a}$. Thick dotted, thin dotted, thick solid and thin solid curves denote the results with the parameters for cases I, II, III and IV, respectively.

modeled curves are most sensitive to $F_{\mathrm{n}}$ and $K_{\mathrm{b}}$. To examine the sensitivity of CT plots for cases I-IV to changes in $F_{\mathrm{n}}$, the results with $F_{\mathrm{n}}$ changes by $\pm 15 \mathrm{~m}^{-2}$, approximately the variation of $F_{\mathrm{n}}$ among our cases, are also plotted in Figure 8. In regions with relatively high $(>70 \%)$ ice cover, the resulting differences in $\Delta T$ were $<0.1^{\circ} \mathrm{C}$. This is much smaller than the observed $\Delta T$ difference among cases $\mathrm{I}-\mathrm{IV}$, which was caused by both $F_{\mathrm{n}}$ and $K_{\mathrm{b}}$ differences. Thus, the observed $\Delta T$ difference is primarily due to $K_{\mathrm{b}}$.

Figure 10 shows the ratio of heat used for ice melt to heat input into open water for cases I-IV in the model. The heat ratio also converges asymptotically, with a timescale of 10 days (Ohshima and Nihashi, 2005). This indicates that the distribution of upper-ocean heat between sea-ice melt and upper-ocean heating can be determined by ice concentration. In regions of relatively high (>70\%) ice cover, the total heat input to open water is distributed $80-95 \%$ to ice melting and $5-20 \%$ to upper-ocean heating during the Arctic summer. Toole and others (2010) proposed that $76 \%$ of total heat into open water went to bottom melt, based on the result from a one-dimensional mixed-layer model, which is consistent with the observation by ITP and IMB from June to early September 2007. Over that observational period, ice concentration averaged $\sim 60 \%$. Their result supports our estimation of heat balance between ice melting and ocean heating.

\subsubsection{Bulk heat transfer coefficient in the ice-upper- ocean system, $K_{\mathrm{b}}$}

The $K_{\mathrm{b}}$ estimated by our model is a bulk heat transfer coefficient in the ice-upper-ocean system. However, McPhee (1992) and McPhee and others (2003) estimated

Table 3. The estimated $K_{\mathrm{b}}$ for ITP3/IMB2005B, ITP6/IMB2006C, ITP13/IMB2007E and ITP18/IMB2007F. Wind speed data used in Figure 12 are averaged in the bottom row

\begin{tabular}{|c|c|c|c|c|}
\hline & ITP3/IMB2005B & ITP6/IMB2006C & ITP13/IMB2007E & ITP18/IMB2007F \\
\hline$K_{\mathrm{b}}\left(10^{-5} \mathrm{~m} \mathrm{~s}^{-1}\right)$ & 2.4 & 2.8 & 2.0 & 4.6 \\
\hline Area for wind & $74-76^{\circ} \mathrm{N}, 130-140^{\circ} \mathrm{W}$ & $75-77^{\circ} \mathrm{N}, 135-145^{\circ} \mathrm{W}$ & $75-77^{\circ} \mathrm{N}, 130-140^{\circ} \mathrm{W}$ & $75-76^{\circ} \mathrm{N}, 140-145^{\circ} \mathrm{W}$ \\
\hline
\end{tabular}


the heat transfer coefficient using the eddy correlation method in the Arctic Ocean. $K_{\mathrm{b}}$ in this study corresponds to $C_{h} \times U_{\tau}$ in their study $\left(C_{h}\right.$ : heat transfer coefficient; $U_{\tau}$ : friction velocity). The estimated $K_{\mathrm{b}}$ in McPhee (1992) and McPhee and others (2003) was $3.1 \times 10^{-5} \mathrm{~m} \mathrm{~s}^{-1}$, which is of the same order as that estimated in this study. Based on results from the Antarctic Ocean, Nihashi and Ohshima (2008) proposed that $K_{\mathrm{b}}$ was proportional to the cubed or squared wind speed (friction velocity). Here we examine the relationship between the estimated $K_{\mathrm{b}}$ listed in Table 3 , and wind speed in the Arctic Ocean.

$K_{\mathrm{b}}$ can also be estimated based on data from ITP and IMB. Equation (4) can be obtained by canceling $A_{\mathrm{i}}$ from Equation (2).

$$
K_{\mathrm{b}}=-\frac{\rho_{\mathrm{i}} L_{\mathrm{f}}}{C_{\mathrm{w}} \rho_{\mathrm{w}} \Delta T} \frac{\mathrm{d} h}{\mathrm{~d} t} .
$$

We used the $\Delta T$ averaged from 8 to $12 \mathrm{~m}$ during July and August for each ITP. Rates of bottom melt $(\mathrm{d} h / \mathrm{d} t)$ were calculated from changes in ice flow depth over that period for each co-located IMB.

Figure 11 shows the relationship between estimated $K_{\mathrm{b}}$ and wind speed. The $K_{\mathrm{b}}$ values are those estimated in this subsection for our four cases, along with those estimated above from the ITP/IMB data, and one additional estimate from Inoue and others (2008). The mean wind speed $\left(\overline{U_{w}}\right)$ was calculated from 6 hourly, $10 \mathrm{~m}$ wind $\left(U_{\mathrm{w}}\right)$ from the European Centre for Medium-Range Weather Forecasts (ECMWF) Interim Re-analysis (ERA-Interim) over the areas given in Tables 2 and 3, for the period from 5 days before observations began to the end of the observation period. The quantities $\overline{U_{w}{ }^{2}}$ and $\overline{U_{w}{ }^{3}}$ are the mean of $U_{w}{ }^{2}$ and $U_{w}{ }^{3}$ over the same area and time periods. $K_{\mathrm{b}}$ and surface wind speed are positively correlated, consistent with the results from the Antarctic Ocean reported by Nihashi and Ohshima (2008). $K_{\mathrm{b}}$ is more likely to be proportional to $\overline{U_{\mathrm{w}}{ }^{2}}$ and $\overline{U_{\mathrm{w}}{ }^{3}}$ rather than having a linear relationship with $\overline{U_{w}}$. Each of these correlation coefficients is significant at a level of $95 \%$. These results indicate that upper-ocean heat can be used more for ice melting as wind speed increases if other parameters $\left(F_{n}\right.$ $H$ and $h$ ) are constant. Unfortunately, only nine data points were obtained to describe the $K_{\mathrm{b}}$-surface-wind-speed relationship (Fig. 11), so more observational evidence is needed for further discussion. However, it seems that our derived $K_{\mathrm{b}}$ values for cases I-IV are at least realistic.

\subsection{A model with transmitted solar radiation through ponded ice}

\subsubsection{Model description}

In areas of high ice cover, heat input due to solar radiation through the ponded ice area is also effective in heating the upper ocean, as described in section 4. The model that includes this input is schematically shown in Figure 7b. We examined the effect of transmitted solar radiation through ponded ice on the sea-ice melting process by including additional terms related to these parameters in Equation (1), as proposed by Inoue and others (2008):

$$
C_{\mathrm{w}} \rho_{\mathrm{w}} H \frac{\mathrm{d} T}{\mathrm{~d} t}=F_{\mathrm{n}}\left(\tau_{\mathrm{o}} A_{\mathrm{o}}+\tau_{\mathrm{i}} A_{\mathrm{i}}\right)+L_{\mathrm{f}} \rho_{\mathrm{i}}\left(A_{\mathrm{i}} \frac{\mathrm{d} h}{\mathrm{~d} t}+h \frac{\mathrm{d} A_{\mathrm{i}}}{\mathrm{d} t}\right),
$$

where $\tau_{\mathrm{o}}=1-\alpha_{\mathrm{o}}=0.94$ and $\tau_{\mathrm{i}}$ are the transmittance of open water and ponded ice, respectively, and $A_{o}$ is the area fraction of open water. The model does not separately treat
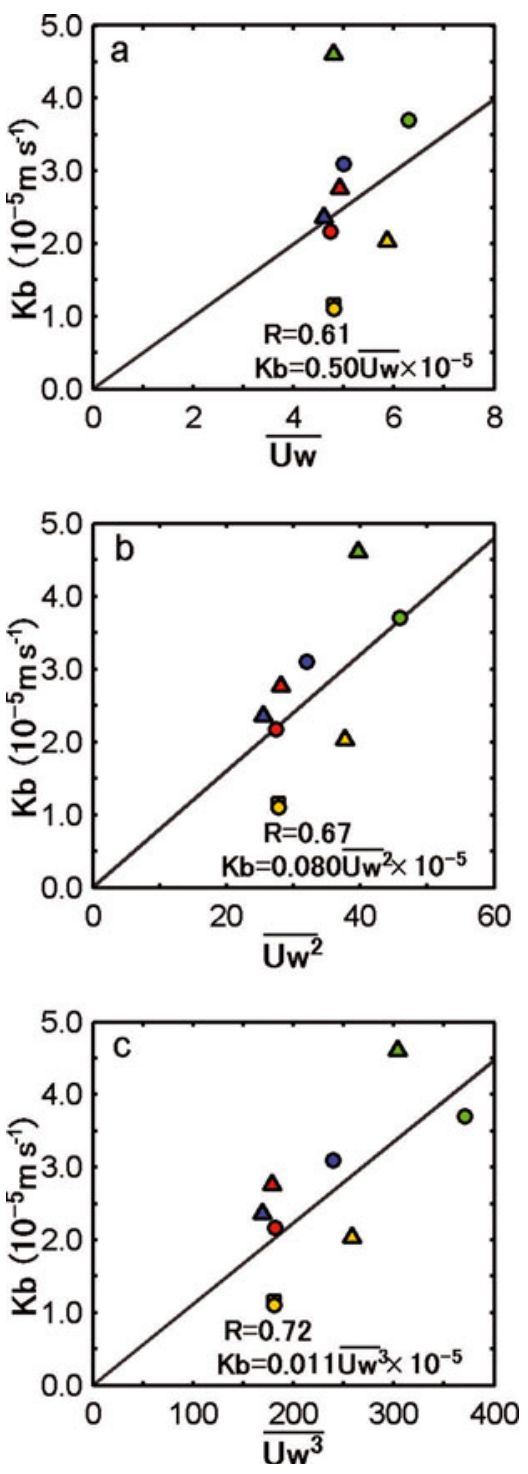

Fig. 11. Scatter plots of the bulk heat transfer coefficient, $K_{\mathrm{b}}$, versus wind speed. Six-hourly $10 \mathrm{~m}$ wind speed data from ERA-Interim provided by ECMWF over the period from 5 days before observations began to the end of the observation $\left(\overline{U_{w}}\right)$ for the study area noted in Tables 2 and 3 are used in (a). $\overline{U_{w}{ }^{2}}$ and $\overline{U_{w}{ }^{3}}$ by averaging $U_{\mathrm{w}}{ }^{2}$ and $U_{\mathrm{w}}{ }^{3}$ over that period for each area are used in (b) and (c), respectively. Solid line is a least-squares fittings line. Blue, red, yellow and green dots indicate results from a cruise on the Healy in 2005 (Inoue and others, 2008), cases I, II and III, respectively. Yellow squares indicate results from case IV. Blue, red, yellow and green triangles indicate results from ITP3/IMB2005B, ITP6/ IMB2006C, ITP13/IMB2007E and ITP18/IMB2007F, respectively.

transmission through the ponds, but rather accounts for a combined transmission through the ponds and bare ice. The initial conditions are the same as in the previous model (section 5.1).

With this version of the model, the modeled $\Delta T$ is greater than 0 , even for $A_{i}=1$, due to transmitted solar radiation through the ponded ice. The modeled CT relationship can be used to estimate solar radiation transmittance through the ice $\left(\tau_{\mathrm{i}}\right)$ by least-squares fitting the observed CT plots. Curves with the values of $\tau_{\mathrm{i}}$ noted in Figure 8 provide the best fit to the observed $\mathrm{CT}$ plots. In the FYI region (case IV), the estimated $\tau_{\mathrm{i}}$ was much larger than in the MYI region (cases I, II and III). 

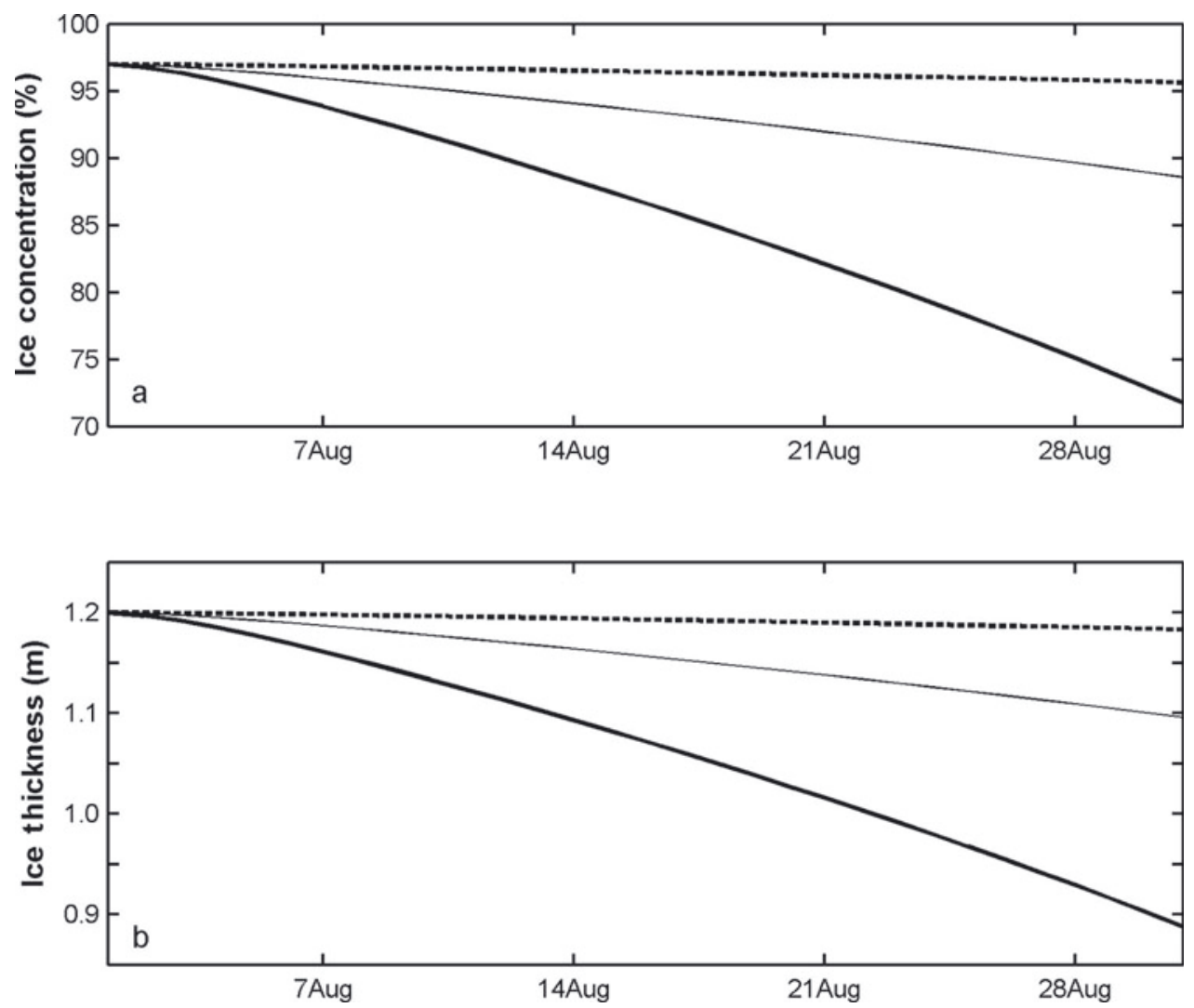

Fig. 12. Time evolution of ice concentration (a) and sea-ice thickness (b) in August calculated from the ice-upper-ocean coupled model. Time integration is done with Equations (5), (2) and (3). Initial ice concentration and ice thickness are set at $97 \%$ and $1.2 \mathrm{~m}$, respectively. $F_{\mathrm{n}}$ and $K_{\mathrm{b}}$ were set at $120 \mathrm{~W} \mathrm{~m}^{-2}$ and $2.0 \times 10^{-5} \mathrm{~m} \mathrm{~s}^{-1}$. Thick dotted curves denote the case without the effect of solar radiation transmittance through the ice $\left(\tau_{i}=0.0\right)$. Thin solid and thick solid curves denote the cases with the effect of solar radiation transmittance through the ponded ice, calculated using $\tau_{\mathrm{i}}=0.15$ (corresponding to thick multi-year ice) and $\tau_{\mathrm{i}}=0.5$ (corresponding to thin first-year ice), respectively.

\subsubsection{Results}

The model approximately describes the heat balance of the ice-upper-ocean system that includes heat input through ponded ice, as well as directly into open water (red curves in Fig. 8). Our results indicate that solar radiation transmittance through the ice is highly dependent on seaice thickness. The anomalously high $\Delta T$ in case IV can be explained by the large solar radiation transmittance through the ponded thin first-year ice. A possible explanation for the $\tau_{\mathrm{i}}$ differences among the MYI regions of cases I, II and III is the melting stage of sea ice (i.e. fraction and depth of melt ponds).

Perovich (2005) estimated that the heat transmittance through ponded multi-year ice was 0.16 during the melt season, based on the sea-ice observations of a year-long field experiment (SHEBA). Inoue and others (2008) estimated the solar radiation transmittance of melt ponds and multi-year ice as 0.55 and 0.09, respectively, based on sea-ice and ocean observation by USCGC Healy in 2005. Because melt ponds covered $25 \%$ of the sea-ice area during that cruise, solar radiation transmittance of ponded ice area is $\sim 0.21\left(=(0.55 \times 0.25)+[0.09 \times(1-0.25)]\right.$, i.e. $\left(\tau_{\text {pond }} \times\right.$ pond fraction $)+\left[\tau_{\text {ice }} \times(1-\right.$ pond fraction $\left.\left.)\right]\right)$. These results are consistent with our estimation of transmittance through the ponded MYI region. There was no observation of solar radiation transmittance of thin first-year ice $(h \sim 0.7 \mathrm{~m})$. However, transmittance of thinner ice would be larger than that of thick ice, because radiance in ice rapidly decreases with depth as shown by Perovich and others (1998).

\subsection{Effects of transmitted solar radiation through ponded ice on the acceleration of sea-ice melting}

Observed higher $\Delta T$ is a consequence of solar radiation transmittance through ponded ice, as suggested above. The evolution of ice concentration and ice thickness can be controlled by heat input through the ice as well as from open water. If a time integration is done using Equations (5), (2) and (3), the time evolution of ice concentration and ice thickness is obtained. Figure 12 shows the changes over time of ice thickness and ice concentration for three cases of ice solar radiation transmission. Solar radiation transmittance through the ice, $\tau_{\mathrm{i}}$, is set at 0.0, 0.15 and 0.5 . Initial ice concentration and ice thickness are set at $97 \%$ and $1.2 \mathrm{~m}$, respectively. $F_{\mathrm{n}}$ and $K_{\mathrm{b}}$ were set at $120 \mathrm{~W} \mathrm{~m}^{-2}$ and $2.0 \times 10^{-5} \mathrm{~m} \mathrm{~s}^{-1}$, corresponding to typical summertime values in the Arctic.

In calculations including solar radiation transmitted through the ice, sea ice decayed rapidly. For thin first-year ice $\left(\tau_{\mathrm{i}}=0.5\right)$, both ice thickness and ice concentration decreased about three times as much as they did in multiyear ice $\left(\tau_{i}=0.15\right)$. In contrast, in calculations without solar radiation transmission through the ice, the ice thickness and ice concentration hardly changed. As noted by Inoue and others (2008), even in MYI regions $\left(\tau_{\mathrm{i}}=0.21\right)$ the amplification of ice-albedo feedback by transmitted solar radiation through ponded ice is significantly larger than that of warming perturbation caused by doubled $\mathrm{CO}_{2}$ forcing. In thin FYI areas $\left(\tau_{\mathrm{i}}=0.5\right)$, this ice-albedo feedback is much stronger due to the larger heat input through the ice. 


\section{SUMMARY AND DISCUSSION}

Sea-ice melting processes were inferred from in situ sea-ice and ocean condition data obtained during the Arctic research cruises of the CCGS Louis S. St-Laurent and R/V Polarstern in the summers of 2006 and 2007. We examined the relationships between ice concentrations observed by on-board ice watches and temperatures above freezing $(\Delta T)$ in the surface mixed layer obtained from CTD and XCTD data, because ice concentration and the $\Delta T$ relationship are consequences of the heat balance in the ice-upper-ocean coupled system, which is maintained by solar radiation, seaice melting, and heat storage in the ocean mixed layer. Using spatially averaged data $(25 \mathrm{~km})$, ice concentration and temperature plots (CT plots) showed negative correlations. This indicates that as ice concentration decreases, the upper ocean becomes warmer from higher absorption of solar radiation, which, in turn, further promotes ice melting (icealbedo feedback). Additionally, $\Delta T$ showed a positive bias when the region was almost completely ice-covered. This indicates that solar radiation transmittance through ponded ice affects upper-ocean warming, which promotes sea-ice melting, particularly in areas of high ice cover. Using simple regression curves applied to the observed CT plots, we separately evaluated the surface water heating caused by heat input through open water and by heat input through ponded ice. Heat input through ice was found to contribute more to ice melting than did heat input through open water when the ice concentration was more than $82-88 \%$ in MYI regions and 65\% in FYI regions.

We developed a simple model to clarify the observed ice concentration and temperature relationships. The relationships between ice concentration and surface mixed-layer temperature derived from our model are consistent with the observed relationships. By comparing the observed CT plot and the model, the bulk heat transfer coefficient between ice and ocean $\left(K_{\mathrm{b}}\right)$ and transmitted solar radiation through the ice were estimated. The estimated $K_{\mathrm{b}}$ increased with increasing wind speed. This result indicates that more of the total heat input into the upper ocean can be used for ice melting as wind speed increases. Substantial differences in transmission were found between first-year ice $(h=0.7 \mathrm{~m})$ and multi-year ice $(h=1.2 \mathrm{~m})$. Transmitted solar radiation through thin ponded first-year ice was estimated to be approximately three times larger than that through thick ponded multi-year ice. The time evolution of sea-ice decay calculated from the model suggested that solar radiation transmittance through ponded ice is amplified by the ice-albedo feedback mechanism, particularly in thin ice regions.

Over the past few decades Arctic sea-ice cover has decreased dramatically (Comiso and others, 2008). Due to the large contrasts in albedo between sea ice $(>0.6)$ and open water $(\sim 0.06)$, an increase in the open-water fraction enhances solar heat input to the upper ocean, which promotes ice melting. This ice-albedo feedback mechanism accelerates sea-ice decay in the Arctic Ocean (Perovich and others, 2007). As well as open-water areas, in regions of high ice cover, ponded areas act as heat sources due to transmitted solar radiation. Recently, the extent of old and thick multi-year ice has been rapidly reduced (Maslanik and others, 2007; Kwok and Rothrock, 2009; Kwok and others, 2009). As thin ice increases in the Arctic Ocean, the average solar radiation transmittance by ponded areas during the melting season will also increase, as suggested in this study. Thus, even if the extent of open water does not increase, heat input to the upper ocean will be enhanced and ice melt accelerated in an Arctic with an increasing seasonal ice zone area.

\section{ACKNOWLEDGEMENTS}

We are greatly indebted to the officers and crew of the CCGS Louis S. St-Laurent and R/V Polarstern, and to the scientists and technicians who collected the data. Comments from the scientific editor, S. Hudson, and two anonymous reviewers were very helpful for improving the manuscript. We thank A. Proshutinsky who is a collaborator on the CCGS Louis S. St-Laurent science cruise and supported by US National Science Foundation (NSF) grant No. OPP-0424864. We also thank U. Schauer who is principal investigator on the R/V Polarstern science cruise. We are deeply indebted to S. Nishino and A. Orlich for their help with observation. We acknowledge S. Nihashi for discussion. Support was also provided by the Japan Agency for Marine-Earth Science and Technology (M.I., J.I., K.S., T.K., J.H.), Fisheries and Oceans Canada (S.Z., F.M., E.C.), the NSF (J.H.) and the International Arctic Research Center (J.H.). The ITP data were collected and made available by the Ice-Tethered Profiler Program based at the Woods Hole Oceanographic Institution (http://www.whoi.edu/itp).

\section{REFERENCES}

Comiso, J.C., C.L. Parkinson, R. Gersten and L. Stock. 2008. Accelerated decline in the Arctic sea ice cover. Geophys. Res. Lett., 35(1), L01703. (10.1029/2007GL031972.)

Ebert, E.E., J.L. Schramm and J.A. Curry. 1995. Disposition of solar radiation in sea ice and the upper ocean. J. Geophys. Res., $\mathbf{1 0 0}(\mathrm{C} 8), 15,965-15,975$

Eicken, H., M. Lensu, M. Leppäranta, W.B. Tucker, III, A.J. Gow and O. Salmela. 1995. Thickness, structure and properties of level summer multi-year ice in the Eurasian sector of the Arctic Ocean. J. Geophys. Res., 100(C11), 22,697-22,710.

Hibler, W.D., III. 1979. A dynamic thermodynamic sea ice model. J. Phys. Oceanogr., 9(7), 815-846.

Inoue, J., T. Kikuchi, D.K. Perovich and J.H. Morison. 2005. A drop in mid-summer shortwave radiation induced by changes in the ice-surface condition in the central Arctic. Geophys. Res. Lett., 32(13), L13603. (10.1029/2005GL023170.)

Inoue, J., T. Kikuchi and D.K. Perovich. 2008. Effect of heat transmission through melt ponds and ice on melting during summer in the Arctic Ocean. J. Geophys. Res., 113(C5), C05020. (10.1029/2007JC004182.)

Key, J.R. 2001. Streamer user's guide. Madison, WI, University of Wisconsin. Cooperative Institute for Meteorological Satellite Studies.

Krishfield, R., J. Toole, A. Proshutinsky and M.-L. Timmermans. 2008. Automated ice-tethered profilers for seawater observations under pack ice in all seasons. J. Atmos. Ocean. Technol., 25(11), 2091-2105.

Kwok, R. and D.A. Rothrock. 2009. Decline in Arctic sea ice thickness from submarine and ICESat records: 1958-2008. Geophys. Res. Lett., 36(15), L15501. (10.1029/2009GL039035.)

Kwok, R., G.F. Cunningham, M. Wensnahan, I. Rigor, H.J. Zwally and D. Yi. 2009. Thinning and volume loss of the Arctic Ocean sea ice cover: 2003-2008. J. Geophys. Res., 114(C7), C07005. (10.1029/2009JC005312.)

Maslanik, J.A., C. Fowler, J. Stroeve, S. Drobot and H.J. Zwally. 2007. A younger, thinner Arctic ice cover: increased potential 
for rapid, extensive ice loss. Geophys. Res. Lett., 34(24), L24501. (10.1029/2007GL032043.)

McPhee, M.G. 1992. Turbulent heat flux in the upper ocean under sea ice. J. Geophys. Res., 97(C4), 5365-5379.

McPhee, M.G., T. Kikuchi, J.H. Morison and T.P. Stanton. 2003. Ocean-to-ice heat flux at the North Pole environmental observatory. Geophys. Res. Lett., 30(24), 2274. (10.1029/ 2003GL018580.)

Nihashi, S. and K.I. Ohshima. 2008. Bulk heat transfer coefficient in the ice-upper ocean system in the ice melt season derived from concentration-temperature relationship. J. Geophys. Res., 113(C6), C06008. (10.1029/2007JC004127.)

Nihashi, S., K.I. Ohshima, M.O. Jeffries and T. Kawamura. 2005. Seaice melting processes inferred from ice-upper ocean relationships in the Ross Sea, Antarctica. J. Geophys. Res., 110(2), 1-12.

Ohshima, K.I. and S. Nihashi. 2005. A simplified ice-ocean coupled model for the Antarctic ice melt season. J. Phys. Oceanogr., 35(2), 188-201.

Ohshima, K.I., K. Yoshida, H. Shimoda, M. Wakatsuchi, T. Endoh and M. Fukuchi. 1998. Relationship between the upper ocean and sea ice during the Antarctic melting season. J. Geophys. Res., 103(C4), 7601-7615.

Perovich, D.K. 2005. On the aggregate-scale partitioning of solar radiation in Arctic Sea Ice during the SHEBA field experiment. J. Geophys. Res., 110(C3), C03002. (10.1029/ 2004JC002512.)
Perovich, D.K., C.S. Roesler and W.S. Pegau. 1998. Variability in Arctic sea ice optical properties. J. Geophys. Res., 103(C1), 1193-1208.

Perovich, D.K., B. Light, H. Eicken, K.F. Jones, K. Runciman and S.V. Nghiem. 2007. Increasing solar heating of the Arctic Ocean and adjacent seas, 1979-2005: attribution and role in the icealbedo feedback. Geophys. Res. Lett., 34(19), L19505. (10.1029/2007GL031480.)

Perovich, D.K., J.A. Richter-Menge, K.F. Jones and B. Light. 2008. Sunlight, water, and ice: extreme Arctic sea ice melt during the summer of 2007. Geophys. Res. Lett., 35(11), L11501. (10.1029/ 2008GL034007.)

Perovich, D.K. and 7 others. 2009. Transpolar observations of the morphological properties of Arctic sea ice. J. Geophys. Res., 114, C00A04. (10.1029/2008JC004892.)

Steele, M. 1992. Sea ice melting and floe geometry in a simple iceocean model. J. Geophys. Res., 97(C11), 17,729-17,738.

Toole, J.M., M.-L. Timmermans, D.K. Perovich, R.A. Krishfield, A. Proshutinsky and J.A. Richter-Menge. 2010. Influences of the ocean surface mixed layer and thermohaline stratification on Arctic Sea ice in the central Canada Basin. J. Geophys. Res., 115(C10), C100018. (10.1029/2009JC005660.)

Worby, A.P., I. Allison and V. Dirita. 1999. A technique for making ship-based observations of Antarctic sea ice thickness and characteristics. Part I. Observational techniques and results. Antarct. CRC Res. Rep. 14 